Bull. Geol. Soc. Finland 41, 152-133 (1969)

\title{
MORPHOLOGY, MODE OF FORMATION, AND DIAGENETIC CHANGES IN FRAMBOIDS
}

\author{
J. Kalliokoski * and L. Cathles ** \\ * Department of Geology and Geological Engineering, Michigan Technological University, Houghton, Michigan \\ ** Department of Geological and Geophysical Sciences, Princeton University, Princeton, New Jersey
}

\section{ABSTRACT}

Pyrite framboids represent cubic close packed supermolecular colloid aggregates or "crystals», probably formed by a process of coacervation and particulation due to the reaction of ferruginous humic acid with biogenic $\mathrm{H}_{2} \mathrm{~S}$. The structures are enlarged and show morphological changes due to later diagenetic effects.

\section{Introduction}

Pyrite framboids represent the most abundant form of iron sulphide in sedimentary rocks. Their structures are cubic close packed supermolecular colloid aggregates or "crystals» that show morphological changes due to later diagenetic alteration effects (Figure 1,2). In that the literature on the origin, morphology, distribution, and significance of framboids has grown quite voluminous, the reader is referred to the summaries to be found in papers by Love (1967), Papunen (1966), Love and Amstutz (1966), and Honjo, Fischer, and Garrison (1965).

Love and Amstutz (1966) and Love (1967) have presented much new data bearing on the question of genesis and morphology of framboids, but because their outlook, evaluation of data, and conclusions differ from those of the authors, it seems worthwhile to reconsider this very complicated problem. This paper, then, is an attempt to seek clarification for a large body of seemingly random facts by emphasizing a few key observations and supporting these with other kinds of published or unpublished data. Hopefully the hypotheses will be susceptible to evaluation by experimentation.

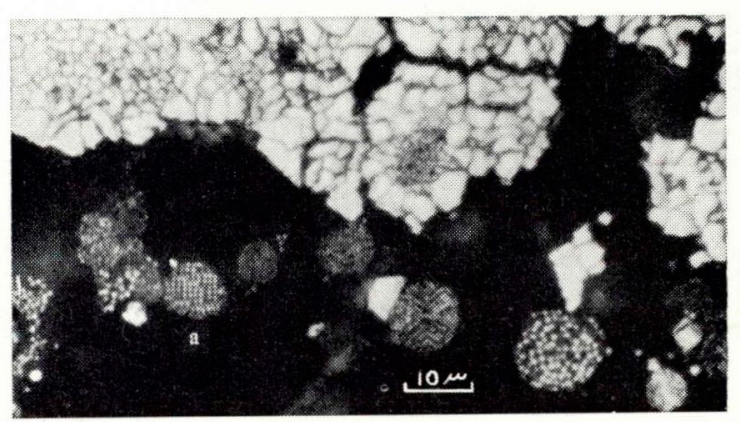

Fig. 1. Framboidal colloid crystals in carbonate matrix (black). Pattern in framboid $a$, viewed normal to (100), shows limits of superimposed layers. At top center a framboid overgrown with crystalline pyrite; at top left, a recrystallized and enlarged framboid. All specimens of Leicester Marcasite Member, N. Y., unless otherwise indicated. 


\section{Terminology}

Framboids are raspberry-like aggregates, from less than 4 microns to more than 25 microns in diameter, made up of $1 / 2$ to 5 micron grains, or granules, of pyrite. Framboids, in turn, can form 0.2 to $0.7 \mathrm{~mm}$ clusters (Figure 4), the »Rogenpyrits» of Fabricius (1961). Two clusters may be jointed as a dumbell.

In morphologically unaltered framboids the constituent spherical pyrite granules are packed with geometric regularity (Figure 3, 6), and because the granules fall within the colloid grainsize and are considerably larger than molecules, the geometric structure can be defined as a supermolecular colloid crystal. If subsequent alteration disturbs or destroys this regular packing, the framboid can lose its crystal morphology (Figure $5,8,10)$.

The term »crystal» is suggested by current useage in colloid chemistry. However, care should be taken that all of the connotations of the term »crystal» are not unconsciously and uncritically applied to colloid crystals. It is possible for example, that the ordering mechanism of the granule in framboids, and perhaps in other colloid crystals, are those of surface tension, and are not electrostatic field forces as in normal crystals. If this is so, the terms »colloid clump» or agglomeration» might be more appropriate. However, in this paper, we shall follow the colloid chemists' terminology.

\section{Chemical Composition of Framboids}

The work of Berner indicates that the initial iron sulphide formed in sedimentary environments is tetragonal $\mathrm{FeS}$ which subsequently alters to pyrite (1964). Thus, one may presume that the chemical reactions responsible for framboid formation also produced tetragonal FeS, and not the pyrite which we now observed. It is important to note that probably none of the framboids that we now see retain their original mineralogical composition.

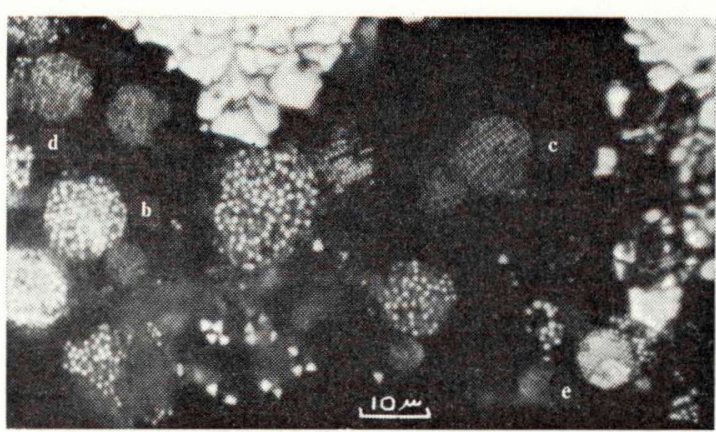

Fig. 2. Framboid colloid crystals in various orientations, all showing cubic close-packing of granules; $b$, viewed normal to (111); $c$, viewed normal to $(100) ; d$, framboid showing both (111) and (100) surfaces; $e$, oblique view of (100) layers. Framboids near the center consist of octahedral granules and do not exhibit the ordered packing characteristic of the others.
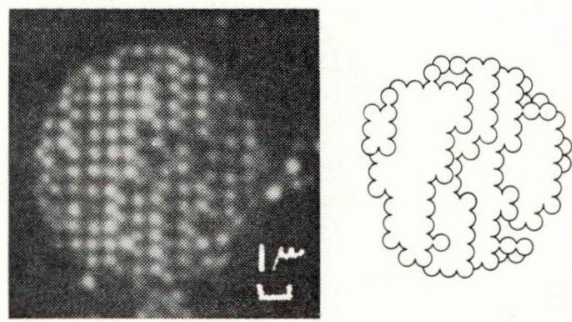

Fig. 3. (Left) enlargement of framboid $c$ of Fig. 2; (Right) Packing arrangement of granules, viewed normal to (100), drawn with the aid of a glass ball replica of $c$.

All studies of framboids show that the existing sulphide species is pyrite. For example, Wilson (1966) found framboids to have the following characteristics: they are non-separable on the Frantz isodynamic separator; they are unaffected by a strong magnetic field in a glass settling tube; a hand-picked concentrate shows only pyrite lines by $\mathrm{x}$-ray diffraction; and an electron microprobe analysis of several framboids in a polished mount showed these to have the chemical composition of pyrite.

There are references in the literature to framboids of chalcopyrite or of other sulfides, but all of these are probably pseudomorphs after pyrite. One exception requiring more study is a framboid-sized »sphalerite globulite with uniformly 


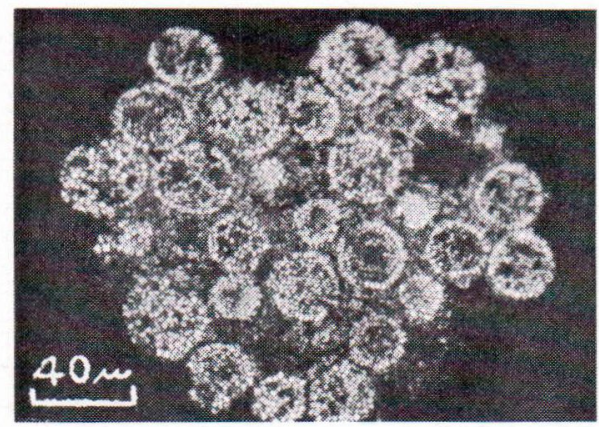

Fig. 4. Polished section of framboid cluster, with an inconspicuous nonmetallic covering. Note similar maximum diameters of framboids and similar grain size of recrystallized granules. Wabana, Nfld.

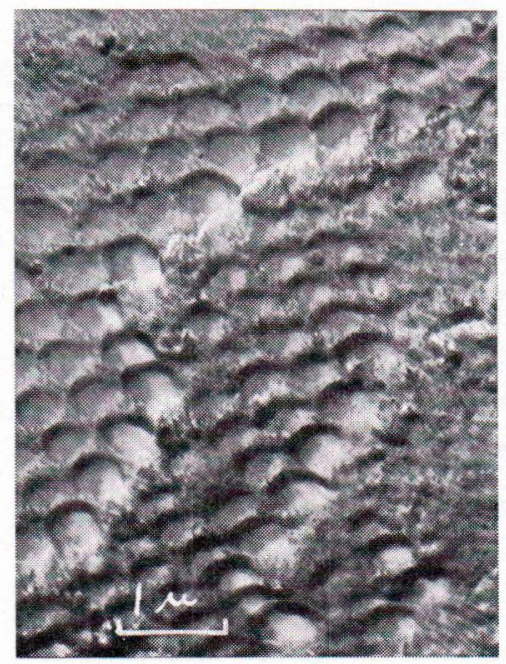

Fig. 6. Electron photomicrograph showing three closepacked sheets of granules, arranged in cubic closepacking, viewed normal to (111). Slight suggestion of facetting in granules; ellipticity due to curling of carbon replica.

Fig. 8. Overgrown and enlarged framboids. In the smaller framboid, the light colored outermost granules have darker overgrowths that extend outward as rods. Note that there is no grain boundary between the lighter granule and its darker overgrowth. In the larger framboid all granules are much larger, and the overgrowths are less radial. The grey sulfide is probably marcasite. Nitric acid etch. Wabana, Nfld.

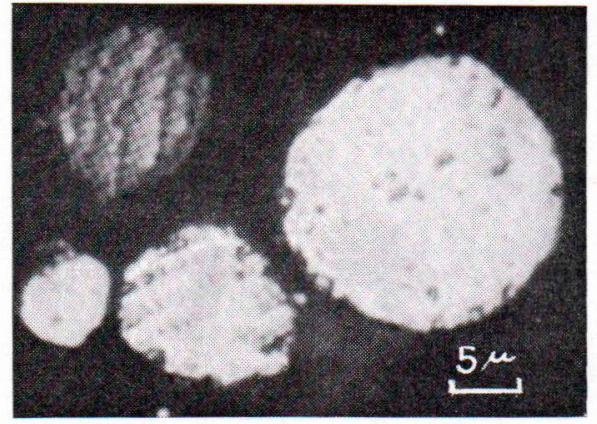

Fig. 5. Variously altered framboids. Oblique view of $(100)$ layers in one; vestiges of original structure in another; lack of framboidal structure in the third.
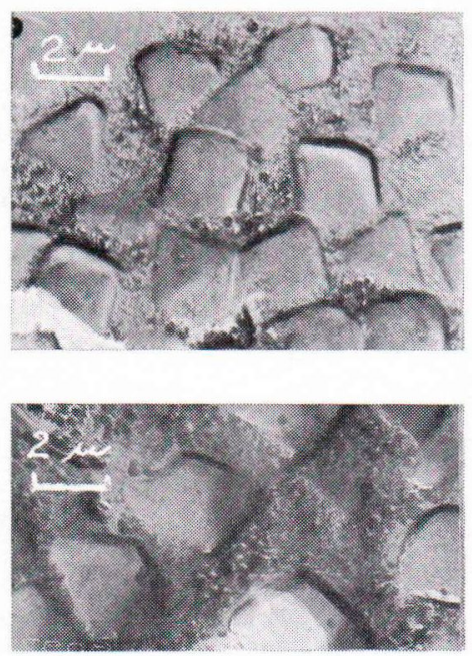

Fig. 7. Electron photomicrographs showing octahedral shape of pyrite granules.

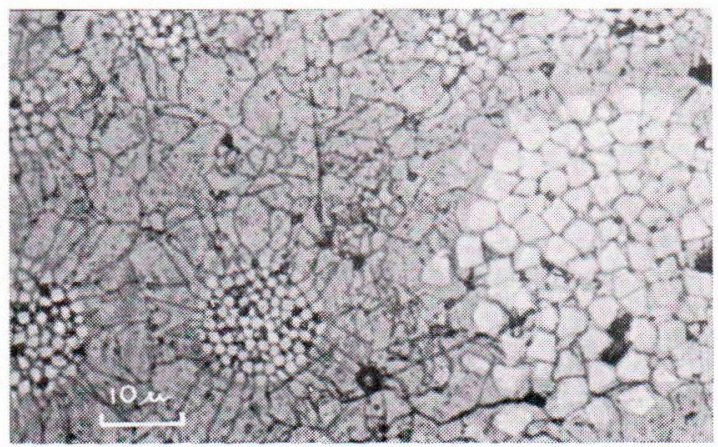


granular texture», from the Iokun'zh deposit, recorded by Lebedev in a retouched photograph (1967, p. 17).

\section{Environment of Framboid Formation}

Papunen (1966, p. 124) has described framboids that have formed in an environment rich in humic acid, i.e., in organic matter having a colloidal nature: »The humus with absorbed iron hydroxide can with increasing acidity form spherical coacervations in water. If now there were enough air, the liberated iron would precipitate as limonite, bog iron ore. But... in the bog the bottom waters can also be oxygen-deficient and can contain hydrogen sulfide abundantly. This reacts with liberated iron hydroxide forming iron sulfide, the reaction occurs between the iron hydroxide in a humus drop and the hydrogen sulfide in water. Crystallization products, framboidal pyrite spherules, with their varying sizes resemble small emulsion drops (type »oil in water»).»

As further evidence of the control by organic debris on framboids, the senior author has noted elsewhere that the pyrite of pyritized fossil matter in the Wabana pyrite bed is abundantly framboidal, whereas the pyrite of adjoining pyritized hematite-chamosite oolites is structureless, granular, or fibrous (Kalliokoski, 1966, p. 880). The correlation is too perfect to be fortuitous. It should be pointed out, however, that many instances are known in which the pyrite in carbonaceous sedimentary rocks is micro-colloform rather than framboidal. Thus, the mere presence of carbonaceous matter does not seem to be sufficient to cause iron sulfide to assume the framboidal form.

The hypothesis of Papunen encounters the difficulty in the very rare instances in which framboids have been described from hydrothermal environments, such as those listed by Love and Amstutz (1966, p. 279) and by Lebedev (1967, p. 15). Does this mean that these thermal waters contained organo-colloidal substances as well, and that, perhaps framboids can be utilized as an indication of geochemical environments?

\section{Coacervation in Colloids, and the Formation of Granules}

In that the process of coacervation, proposed by Papunen to explain framboid formation, is somewhat of an oddity to the geological literature, the following extended statement by De Jong (1959, p. 232) from a book not readily available may be helpful in indicating the nature of this reaction. The comments in square brackets are by the present author:

"If one starts from a sol, that is the solution of the colloid in an appropriate solvent [the humus droplet with its content of iron hydroxide], then according to the nature of the colloid, various changes (temperature, $\mathrm{pH}$, addition of a substance $\left[\mathrm{H}_{2} \mathrm{~S}\right]$ ) can bring about a reduction of the solubility as a result of which a large part of the colloid separates out in a new phase.

"The original one-phase system - the sol - then divides into two phases, one of which is rich in colloid, the other poor.

"The separated colloid-rich phase can either appear in a low dispersed state or in higher dispersed states. In the first case, macroscopic or microscopic investigations allow one to distinguish between crystallization, when obvious crystalline individuals are formed and coacervation, when amorphous liquid drops are formed ...»

A second excerpt from De Jong indicates the gradational nature between crystallization and coacervation (1959, p. 241):

"In this connection the observations of Holwerda are interesting, concerning the separation of edestin from its $\mathrm{NaCl}$ solution on dilution with water. Edestin is a plant globulin which dissolves in $10 \% \mathrm{NaCl}$ and on dilution with water crystallizes out. Holwerda followed this separation under the microscope, water being slowly added during the process. Initially the edestin separates in the form of drops, which however, on the addition of more water are gradually transformed into the typical fairly regular hexagonal shapes of the edestin crystal. Triangular shapes with much rounded corners were observed in the process as transitional shapes which via hexagonal forms with three long and three short sides finally go over into the regular hexagonal form». 


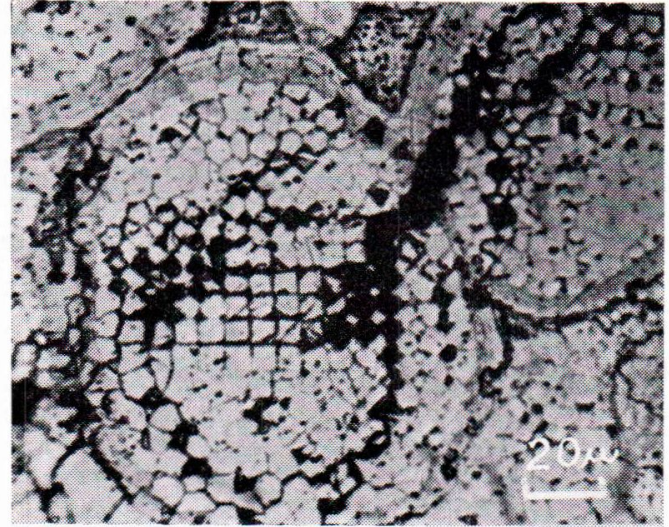

Fig. 9. Part of a cluster showing a framboid with square, hexagonal, and polygonal granule boundary in a random section, perhaps indicative of mutual interference during growth. Note the dark outer zone on the framboid.

This excerpt points out that each granule could have originated as a coacervate droplet in the sol, and then transformed gradually into a small colloid crystal, and finally to iron sulfide which we now observe.

\section{Formation of Framboids}

Papunen suggests that each humus droplet subdivides internally into several coacervate droplets which ultimately will become the granules. Each humus droplet thus forms a framboid in which the particles become ordered according to CCP, due to surface tension effects, as will be shown later. We will also consider the alternative whereby each humus droplet transforms directly into a single granule, these granules then settling out as a distinct phase, clumping and ordering as they do so into framboids and clusters, according to principles we shall discuss later. The first of these hypotheses, advocated by Papunen, might be called the particulation hypothesis; the second, the agglomeration hypothesis. Both hypotheses seem valid, but there is some disagreement among the present authors as to which is the more plausible.

In either case, the humic environment and

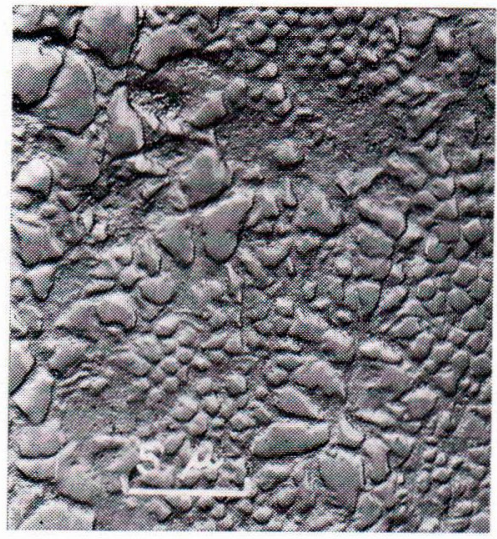

Fig. 10. Variously recrystallized and enlarged granules in framboids. Electron photomicrograph.

coacervation are capable of accounting for several of the phenomena associated with framboids. It can explain why framboids generally have a non-metallic envelope (displaced, suspended, or reaction rejected material) enclosing them (Figure 4,9$)$. It also provides the reason why framboids need not be fossils even though they are so closely associated with organic debris, and why, because of the necessity of an organic-rich environment for their formation, they contain isotopically light sulphur derived from bacterial metabolism.

\section{Framboids as Supermolecular Colloidal Crys- tals}

The ordering of granules in framboids is always CCP (Figures 1, 2, 3, 6), never HCP (Kalliokoski, 1965; Rozentsvit and Epshteyn, 1963). A close-packed, maximally dense structure might be expected, but the preference of CCP over HCP has proved a puzzle. Several hypotheses have been offered, and one in particular may be susceptible to a simple test by a group having a sufficiently powerful microscope.

If the granules are charged, electrostatic ordering is possible. Since the energy of mutual 
attraction of charged spheres is slightly greater in CCP than HCP packing, CCP packing would be preferred. The difference in energy is very slight, however (Luck, Klier, and Wesslau, 1963, give values of $7.2338 \varphi$ for $\mathrm{HCP}, 7.2359 \varphi$ for CCP, $\varphi$ being the energy of mutual attraction), and the efficacy of this ordering mechanism, even assuming its appropriateness, might be doubted.

Luck, Klier, and Wesslau have pointed that surface tension is also an available ordering mechanism. They computed the energy of interactions between various adjacent planes in an supermolecular crystal due to the surface tension attraction of the granules (1963, p. 493):

\begin{tabular}{|c|c|c|}
\hline & HCP & CCP \\
\hline $\begin{array}{l}\text { Surface } \ldots \ldots \ldots \\
\text { Surface energy } \\
G\left[\varphi / a^{2}\right] \ldots \ldots\end{array}$ & $\left|\begin{array}{lllll}0001 & \overline{1} 010 & 10 \overline{1} 1 & \overline{12} 01 & 10 \overline{1} 2 \\
1.73 & 1.84 & 1.89 & 2.12 & 2.10\end{array}\right|$ & $\begin{array}{ll}111 & 001 \\
1.73 & 2.0\end{array}$ \\
\hline
\end{tabular}

The gross aspects of the table might have been expected. In particular (0001) and (111) surfaces have identical energies of attraction, and their energies are less than the energies of interaction of the other crystal plane (those planes having the densest packing are furthest separated from one another and hence it requires less work to separate them).

A crystal will be most stable if it exposes its weakest surfaces and encloses its strongest bonds (maximization of bonding energy). Such crystals will also be those most likely to form. But we notice that only CCP ordering can form a crystal enclosed in minimum energy planes. Hence, in closed forms, such as framboids, preference for CCP is not unexpected if surface tension is the ordering mechanism.

\section{Clusters, or "Rogenpyrits"}

Framboids, in turn, form larger aggregates termed »Rogenpyrits» by Fabricius, who pro- vides the best descriptions of their morphology (1961). These clusters (Figure 4) range from 0.2 to $0.7 \mathrm{~mm}$ in diameter, and each cluster consists of framboids of approximately equal diameter. Yet, in polished sections, adjoining clusters vary in their relative diameters, or in the size or number of their constituent framboids. The diameter of the clusters collected by Fabricius for study are about 50 times that of the constituent framboids. Some of the clusters also show the CCP ordering, that is characteristic of surface tension control (Luck et al, 1963, p. 493).

\section{Dumbells}

»Rogenpyrits» form dumbells, the largest organized form in this sequence of suggested colloidal phenomena. As indicated by Fabricius' photographs, the two »Rogenpyrits» in a dumbell consists of equal sized framboid clusters (1961, Fig. 8). This sizing suggests that the dumbells could not have formed by the adhesion of two randomly formed clusters.

The present writers propose that if the original droplet is sufficiently large, it may undergo several stages of particulation. Thus, it is suggested that in size the largest humus droplet is represented by the cluster. This large droplet subdivided internally into a number of immiscible droplets, each having the size of a framboid; each of these internal droplets, in turn, then underwent further internal coascervation to form granule-sized coascervations, perhaps activated by the reaction of $\mathrm{H}_{2} \mathrm{~S}$ on the iron in the colloid. If the original droplet were smaller, it particulated, not into a cluster, but into a framboid. According to De Jong such a sequential process is possible (De Jong, Fig. 9; Govett, 1966, Fig. 3). The data of Love and Amstutz (1966, Fig. 3) also suggest that at a still smaller size range the droplet will no longer undergo particulation, but instead, will remain as a single granule. This data is strong evidence against the agglomeration hypothesis. 


\section{Agglomeration or Particulation?}

It is felt by one of the current outhors (J.K.) that particulation, and chemical control on the size of the resulting granules, framboids, and clusters are required to account for the observed uniformity in the dimensions and organization of these forms, especially as shown by the clusters.

The other author (L.C.) feels that dynamic, physical considerations may be adequate to account for the rough uniformity in sizing, although perhaps more difficult to see. It is presumed that the granules are nothing other than sulfadized colloidal humus particles, and hence are as uniform in particle size as the original humus colloid. After sulfadization the colloid may begin to settle. Granules stick together by virtue of surface tension when by chance they collide. Ordering is CCP as previously discussed. When all »fast moving» granules are clumped into framboids, the slow-moving framboids can begin to clump into clusters, as they gradually settle in the parent liquid.

It seems reasonable to expect that all framboids will be of the same approximate size, in that each nucleation center or nascent clump will grow by capturing granules (driven by molecular impactbrownian movement) from roughly equal spheres of influence. At first this would presumably be one mean free path length for a granule, and later half the distance between nucleation centers.

The same mechanism can be envisioned to clump framboids into clusters, and clusters into dumbells, surface tension once again forming the glue.

What is not clear to one of the authors (J.K.) is, that if framboids are due to agglomeration, why they should reach some particular limiting size-range before clumping to form a cluster. One might expect to see more evidence of instances in which a cluster had been formed of essentially one size-range of framboids, each framboid having appropriately the same number of granules, but then at a later stage, because of random collision, had incorporated another type of framboid.

Casting further doubt on the agglomeration hypothesis are spherical cluster-size structures photographed by Fabricius (1961, Fig. 6) that consists of a mass of granules, with no internal framboidal organization. It is easier to envision direct particulation mechanism for their formation than some agglomeration mechanism, considering the great number of granules involved, and the collision volume that would be necessary in order to agglomerate this number of particles.

\section{Additional Observations}

Other observations are also perhaps appropriate:

(1) Spherical form of very small crystals, in our instance the granules, is a consequence of the increasing importance of surface tension forces over body forces at small diameters (Buckley, 1951, p. 105-119). Spherical form of the granules also automatically implies that they will adhere to one another because of surface tension, and hence implies the applicability of surface tension ordering mechanism in supermolecular colloid crystals. Crystal form will become prominent as the granules increase in size.

(2) The size of a given spherical granule, or framboid or cluster, cited at an earlier page, cannot be taken as evidence of the size of the original humus drop, droplet, or colloid, in that subsequent alteration has taken place (at least from humus to $\mathrm{FeS}_{2}$, and perhaps even through further overgrowth).

(3) Granules in least altered framboids are all very nearly the same size. There seems to be a kind of upper limit on the number of granules in a framboid in that the diameter of a framboid is generally about ten granules and rarely much exceeds this figure. However, the number may range from 6 to 15. (Fig. 11).

(4) Clusters and framboids settle to the bottom of shells or other confining objects. Thus, they may be used as an indicator of the gravity vector (Honjo, Fischer, and Garrison, 1965).

(5) Some authors have attributed the ordering in framboids to the geometric shape of the granules (Love and Amstutz, 1966). The present authors believe that explanation must lie in another ordering mechanism because 


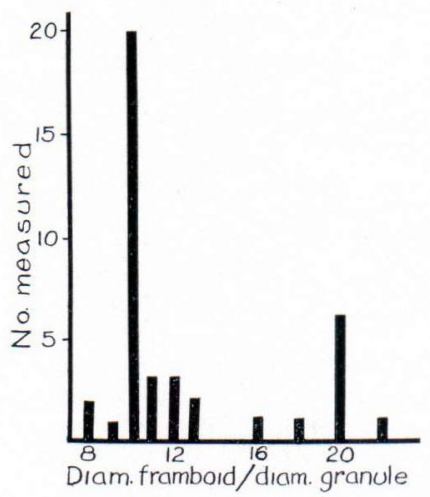

Fig. 11. Histogram showing relationship of framboid diameter to its constituent granule diameter (Wilson, 1966).

(a) not all granules have shape, (b) the shape of granules (when not spherical) is probably governed by post-ordering growth.

\section{Diagenetic Growth of Granules and Fram- boids}

The smallest granules are spherical (Fig. 3, 6), intermediate size granules may be spherical or facetted, and the largest are facetted (Fig. 1, 2, 7). The authors are of the opinion that the above gradational sequence (Figures 3, 9) must represent diagenetic growth of individual pyrite granules, remembering, however, that some of the change from a spherical to facetted form could be due to the crystallization of the original coacervate, without an increase in size, as quoted from De Jong on an earlier page.

As the granules grow, the framboids increase in size (Figures 1, 5, 8, 9). In the process, CCP granule ordering deteriorates (Figures 1,2). Ultimately the framboid may become a solid mass of pyrite in which the structure can be seen only after etching with nitric acid.

Large facetted granules, described in great detail by Love and Amstutz (1966) may originate in two ways. Some of the cubic ones might possibly be the result of the mutual interference during growth (Figure 9). The electron photo- micrographs of octahedra in Figure 7, and those illustrated by Honjo, Fischer, and Garrison (1965, Figure 3) must represent growth of granules of a size at which surface tension no longer controls morphology. Such aggregates of octahedra must develop with a concommitant increase in the size of the adjoining intercrystalline voids. In none of these aggregates do the electron photomicrographs suggest a geometric packing of the octahedra.

Love and Amstutz suggest on the basis of microscopic observation that some framboids consist of closely packed, and crystallographically oriented layers of pyritobedra (1966, p. 289). If true, this would imply that the mechanism responsible for the formation of supemolecular colloid crystals can also control the subsequent lattice orientation of the individual granules to the extent that each framboid becomes organized as essentially a single crystal. However, arguing against the interpretation of Love and Amstutz that framboids consist of oriented pyritohedra is the recent observation by Williams (1968) that the space-filling polyhedron is the tetrakaidecahedron, a 14-face form that shows consirerable resemblance to a pyritohedron, a 12 -face form. Thus, the pyritohedron-like granules in framboids probably owe their origin to mutual interference during growth.

Framboids show a second type of diagenetic modification as well. Figure 8 illustrates an instance in which the outermost granules have served as nuclei for the subsequent outward growth of brownish sulfide. Microprobe analysis by R. Moberly, Jr. (Kalliokoski, 1966, p. 880) of similar brownish overgrowth on framboids in Wabana material shows this to be $\mathrm{FeS}_{2}$, but the intensity of radiation between the yellow and the brown zones differs by a ratio of $28: 27$, suggesting a similar density difference. Thus, the brown overgrowth has been interpreted to be marcasite.

Acknowledgements - These ideas relate back to a stimulating lecture in 1959 by Professor Paul Ramdohr on 
the Rammelsberg ores and to his comments on their intriguing microscopic features. The photographs were taken at Stanford University in 1964 with optical and electron microscopic equipment, made available by Professors A. S. Tetelman and W. D. Nix of the Department of Materials Science. Prof. G. A. Parks of Stanford and Dr. R. C. Erd of the U. S. G. S. were very helpful in the early evolution of some of the ideas. Dr. R. Moberly, Jr., provided the microprobe analyses in 1966. To these and to many others the writers extend their thanks for help, comment, and criticism: to some of the latter we may have been insensitive.

\section{REFERENCES}

Berner, R. A. (1964). Stability fields of iron minerals in anaerobic marine sediments. Jour. Geology, Vol. 72 , p. $826-834$.

Buckley, H. E. (1951). Crystal Growth. John Wiley and Sons, Inc., New York, 571 p.

Bungenberg de Jong, H. G., (1949). Morphology of Coacervates, p. 434-482, in KRUYT, H. R., Editor, Colloid science, Volume II: New York, Elsevier Publishing Co, Inc. 753 p.

FAbricrus, FRANK (1961). Die Strukturen des »Rogenpyrits» (Kössener Schichten, Rät) als Beitrag zum Problem der »Vererzten Bakterien». Geol. Rundsch., Vol. 51, p. 647-657.

Govetr, G. J. S. (1966) Origin of banded iron formation. Geol. Soc. America Bull., Vol. 77, p. 1191-1212.

Honjo, S., Fischer, A. G., and Garrison, R., (1965). Geopetal pyrite in fine-grained limestones. Jour. Sed. Petrology, Vol. 35, p. 480-488.

Kalliokoskr, J. (1965) Framboids: Colloid-crystals of pyrite (abst.). Econ. Geol., Vol. 60, p. 1562.

- (1966). Diagenetic pyritization in three sedimentary rocks. Econ. Geol., Vol. 61, p. 872-885.

KruYt, H. R., Editor. (1949). Colloid Science. Vol. II. Reversible Systems. Elsevier Publishing Company, Inc. $754 \mathrm{p}$.
Lebedev, Lev M., 1967. Metacolloids in Endogenic Deposits. Plenum Press, New York. 298 p.

Love, L. G. and Amstutz, G. C. (1966). Review of microscopic pyrite from the Devonian Chattanooga Shale and Rammelsberg Bandertz. Fortschr. Miner. Vol. 43, p. 273-309.

Love, L. G. (1967), Early diagenetic iron sulfide in Recent sediments of The Wash (England). Sedimentology, Vol. 9, p. 327-352.

Luck, von W., KLier, M., and Wesslau (1963), Kristalligation übermolecularer Bausteine. Naturwissenschaften, Vol. 50, p. 484-494.

Papunen, Heikni (1966) Framboidal texture of the pyritic layer found in a peat bog in SE-Finland. Compt. Rend. Soc Geol. Finland, No. 38, p. 117-125.

Rozentsvit, A. O., and Epshteyn, G. Yu (1963) Crystallization of pyrite from gels of complex composition (Translation) Doklady Akad. Nauk SSSR. Vol. 150, p. $145-147$.

Williams, R. E. (1968). Space-filling polyhedron: its relation to aggregates of soap bubbles, plant cells, and metal crystallites. Science, Vol. 161, p. 276-277. Wilson, Peter L. (1966). The Origin of Framboids in a Recent Sediment. Unpublished Senior Thesis, Princeton University.

Manuscript received, December 20, 1968. 